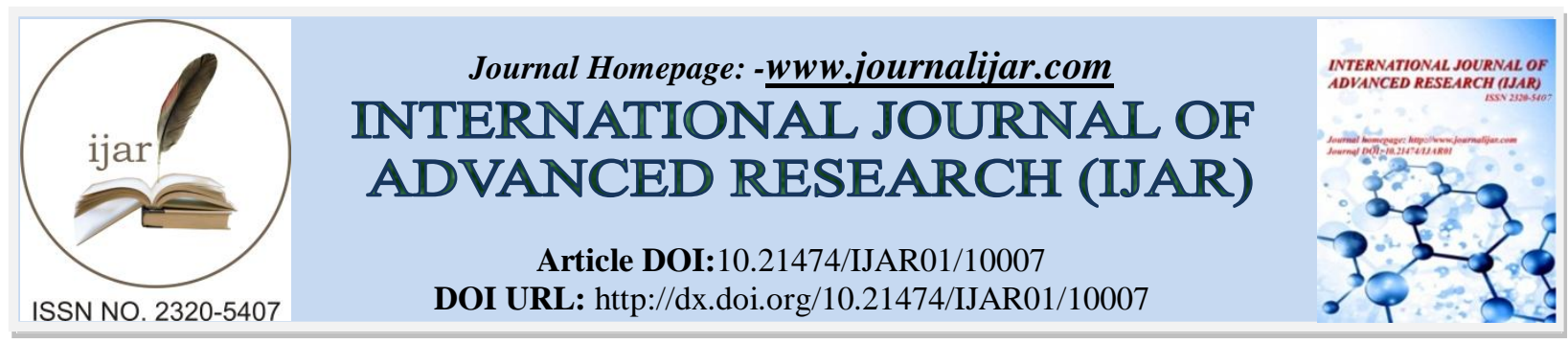

RESEARCH ARTICLE

\title{
CHALLENGES IN MANAGEMENT OF INTESTINAL PERFORATION BY BLUNT ABDOMINAL TRAUMA (URGENT SURGERY VERSUS CONSERVATIVE SURGERY).
}

Ibrahim A. Heggy, Mostafa M. Khairy, Mahmoud Abdou Yassin, Ahmed M. El Teliti.

\section{Manuscript Info}

Manuscript History

Received: 08 September 2019

Final Accepted: 10 October 2019

Published: November 2019

Key words:-

Intestinal perforation, abdominal trauma, conservative, surgery.

\section{Abstract}

Introduction: Bowel perforations are rare conditions following blunt abdominal trauma. Initial clinical examination may be not significant due to delayed peritoneal reaction. The optimal line of management of hemodynamically stable patients with suspected blunt bowel injury, such as mesenteric hematoma, bowel wall edema or fat infiltration, or free fluid for suspected perforation is unclear.

Patients and methods:This study done in zagazig university surgical emergency unit between May 2016 and February 2018. We had 81 patients with suspected bowel perforation after blunt abdominal trauma. The aim of the study:To assess the outcomes of initial conservative therapy and selective delayed surgery in patients with unclear intestinal perforation versus urgent surgical intervention.

Conclusion:The outcome of delayed diagnosis and surgery is not always very bad The rate of missed injuries after early and initial evaluation may be decreased by the use of advanced technology, and the risk of delayed diagnosis will reduced by improvements of intensive care unit

Copy Right, IJAR, 2019,. All rights reserved.

\section{Introduction:-}

The current management of patients with intestinal perforation diagnosed by radiology was the surgery (either laparoscopically or open laparotomy).

During our work in emergency unit we found some patients (who were not fit for anesthesia) start to improve with conservative supportive treatment e.g. cardiac failure, respiratory failure and patients refuse operation, so we decide to make a comparative study between the conservative treatment and delayed surgery with urgent surgical intervention in unclear intestinal perforation in selective cases.

Bowel perforations are rare conditions following blunt abdominal trauma. Initial clinical examination may be not significant due to delayed peritoneal reaction. CT with contrast scans is used in the diagnosis of bowel and mesenteric injury in wide range $[1,2,3]$. However, this is not optimal diagnostic radiologic method for the bowel injury prediction that requiring surgery. The optimal line of management of hemodynamically stable patients with suspected blunt bowel injury, such as mesenteric hematoma, bowel wall edema or fat infiltration, or free fluid for suspected perforation is unclear [4]. Although imaging modalities had been advanced, but potential missed injury may be occurred $[5,6,7,8]$ 
Although initial conservative therapy with selective delayed surgery has an increased risk of complications [9, 10, 11], it may be beneficial in the clarification of precise diagnosis and appropriate treatment in the patients to avoid unnecessary exploration [12]. Additionally, it may also minimize complications, which carries a risk of substantial mortality results.

The role of initial conservative management with delayed selective surgery for patients with blunt bowel perforation diagnosed by radiologic is less clear.

\section{Patients and methods:-}

This study done in zagazig university surgical emergency unit between May 2016 and February 2018. We had 81 patients with suspected bowel perforation after blunt abdominal trauma. Fifty three patients were men and twenty eight were women with the mean age of $41 \pm 15$ years (ranged from, 17-78 years).

All patients were assisted and treated as multiple trauma patients ,resuscitation A,B,C,D,E was applied to all patients , all patients subjected to the following investigations, intervention and imaging for hemodynamic stability of the patients at time of admission,

1. Chest $\mathrm{x}$-ray,erect chest radiograph for air under diaphragm.

2. Nasogastric Tube to discover of Blood or nature of fluid from the stomach also to decrease intra abdominal pressure and congestion.

3. Urinary catheter to rule out urine output and to discover haematuria and fluid chart

4. Rectal examination for rectal bleeding or signs of any associated injury

5. Serial physical abdominal and general Examination (PE)

6. Focused Assessment Sonography Trauma (FAST) and repeated U/S for internal hemorrhage.

7. CT scan with contrast.

8. Repeated physical examination for abdomen and all systems reevaluation again.

All patients were hemodynamically stable and had no neurological or bone or cardiothoracic injury requiring emergency surgery.

We had, group A 44 patients (54\%) received initial conservative nonoperative management which involved NPO and intravenous administration of fluid and antibiotics. During the observation period stage, there was repeated physical examinations and laboratory investigation to re-evaluate and follow up patients' parameter. Also repeated CT contrast scans in all cases between 2, 4 and 7 days after admission. CT scans performed early in first hours in patients with progressive clinical symptoms or bad laboratory parameters.

Delayed surgery was done in selective patients with bad progressive clinical symptoms, deteriorated laboratory parameters, including increases WBC and CRP, and radiological findings positive for definite clear bowel injury, or progression of bowel injury with free perforation after a repeat CT scan.

The group B 37 patients underwent emergency surgery (group B) after supportive treatment. Emergency surgery was done within hours after admission and initial clinical evaluation, positive CT and laboratory finding.

\section{Results:-}

This study included 53 men and 28 women with the mean age of $41 \pm 15$ years (ranged from, 17-78 years). The main clinical symptoms were whole abdominal pain with tenderness and there were 31 patients (38\%) with fever $(\geq 38.4)$

Traffic accidents and falls were the major causes of blunt trauma. Other injuries involved heavy machinery, fighting, or bicycle and playing football. The mean ISS was $(13 \pm 4)$.

Table 1:-demonstrated early physical examinations between the 2 groups.

\begin{tabular}{|l|l|l|}
\hline Clinical pictures & $\begin{array}{l}\text { Group A } \\
\mathrm{N}=44\end{array}$ & $\begin{array}{l}\text { Group B } \\
\mathrm{N}=37\end{array}$ \\
\hline Abdominal pictures & 33 & 27 \\
\hline Bleeding/ rectum & 4 & 5 \\
\hline
\end{tabular}




\begin{tabular}{|l|l|l|}
\hline Abdominal bruises & 17 & 18 \\
\hline Peritoneal signs & 20 & 17 \\
\hline Bradycardia $/<60 \mathrm{~min}$ & 10 & 11 \\
\hline Urine output $<30$ & 16 & 15 \\
\hline
\end{tabular}

Table 2:-The clinical and laboratory characteristics of patients were summarized and there were no differences between the 2 groups

\begin{tabular}{|c|c|c|c|}
\hline Items & $\begin{array}{l}\text { Group A } \\
\mathrm{N}=44\end{array}$ & $\begin{array}{l}\text { Group B } \\
\mathrm{N}=37\end{array}$ & $\mathrm{p}$-value \\
\hline Age (years) & $42.3+\_15.3$ & $39.3+\_14.3$ & 0.397 \\
\hline Sex M/F & $28: 14$ & $23: 12$ & 0.931 \\
\hline $\mathrm{BMI}(\mathrm{kg} / \mathrm{m} 2)$ & $24.1+\_2.8$ & $23.6+\_3.4$ & 0.476 \\
\hline Febrile state $(\mathrm{c})$ & $37.5+-1.4$ & $37.6+-1.5$ & 0.637 \\
\hline Leucocytes no.(103/l) & $7.5+-4$ & $8.5+\_5$ & 0.169 \\
\hline HB. Level $(\mathrm{gm} / \mathrm{dl})$ & $11.3+\_3.3$ & $11.7+\_3.2$ & 0.542 \\
\hline Injury severity scoring & $12.4+\_4.2$ & $13.5+\_4.6$ & 0.271 \\
\hline Combined injury & 13 & 12 & 0.788 \\
\hline $\begin{array}{l}\text { Length of hospital stay } \\
\text { (day) }\end{array}$ & $19+\_23$ & $16+\_15$ & 0.518 \\
\hline \multicolumn{4}{|l|}{$\begin{array}{ll}\text { Radiological signs } \\
\text { numbers }\end{array}$} \\
\hline 1 & 10 & 9 & \\
\hline 2 & 24 & 23 & \\
\hline 3 or more & 10 & 8 & \\
\hline
\end{tabular}

Values are presented in the table +__ standard deviation

The specific radiologic signs included mesenteric fat infiltration,signs of inflammations, mesenteric hematoma, bowel wall thickening or edema, or free peritoneal cavity fluid collection and were collected. Nineteen patients had a single radiologic sign of suspected bowel trauma, 47 patients had 2 signs, and 18 patients had more than 3 sign in both groups.

In the group A, 20 patients (45\%) underwent delayed surgery. After repeat CT scans, 4 patients had definite pneumoperitoneum or bowel ischemia signs and 13 patients had mild, progressive or equivocal findings with aggravation of clinical and laboratory findings. They subsequently underwent delayed surgery (3-4 days after admission). There were 3 patients with no definite equivocal findings after repeat CT scans with contrast and improvement of clinical findings occurs. However, they showed sudden aggravation of clinical symptoms and surgery was done in the fifth day after trauma.

The delayed surgery intervention was performed in the $3 \pm 2$ days (ranged from, 3-5 days) after admission.

In operative finding, negative surgical intervention signs were observed in 5 patients who had only mesenteric hematoma and mesenteric edema intraoperatively 5 of 20, (25\%) without any procedure. Seven patients had definite serosal tears with peritonitis, three had bowel ischemic changes, three had free fecal perforation, and 2 had active bleeding from the bowel and/or mesentery. The affected sites were mostly the small bowel. Operative procedures included bowel resection, primary repair of injury, and control site of bleeding.

During the postoperative period, eight patients (40\%) were complicated, 5 patients developed wound infections, 1 had a prolonged ileus over 7-8 days, and 1patient had intra-abdominal fluid collection treated with percutaneous drainage guided CT. Also, 1 patient was readmitted again after 4 months for adhesive obstructive symptoms, and was treated conservatively.

The remaining 24 patients were improved clinically (symptoms and signs) after continuous conservative management with normal laboratory before discharging. Followed-up at least 2 times every month.

One patient had recurrent abdominal pain during the follow-up, and was treated conservatively. 
In group B 37 patients urgent explored, 15 (40.5\%) no positive finding need surgical procedure. During the postoperative period, 6 patients had wound infections, 3 had prolonged ileus for 7 days, 3 patients had intraabdominal fluid collection discovered by postoperative ultrasound and were treated with percutaneous drainage, and 1 had anastomotic leakage and reoperated. Also we had1 patient complicated by incisional hernia and hernioplasty done 11 months after trauma.Another 1 patient was complicated by adhesive intestinal obstruction 6 months later, and he was treated conservatively.

Table 3:-Clinical pictures after outcome between two groups

\begin{tabular}{|l|l|l|l|}
\hline Items & Group a & Group b & p- value \\
\hline No operation & 24 & - & \\
\hline Operation & 20 & 37 & \\
\hline Negative & $5(20 \%)$ & $15(40.5 \%)$ & 0.129 \\
\hline Ischemia & 3 & 5 & \\
\hline Perforation & 3 & 5 & \\
\hline Serosal tear or injury & 7 & 10 & \\
\hline Active bleeding & 2 & 2 & 0.799 \\
\hline Surgical complication & $8 / 20(40)$ & $15 / 37(40.5)$ & \\
\hline Wound infection & 5 & 6 & \\
\hline Ileus above 7 days & 1 & 3 & \\
\hline Fluid collection(intaabdominal) & 1 & 3 & \\
\hline Adhesive obstruction & 1 & 1 & \\
\hline Leakage from anastomosis & - & 1 & \\
\hline Incisional herniation & - & 1 & \\
\hline
\end{tabular}

Value was presented by number or \%

\section{Discussion:-}

Blunt bowel trauma may result in the formation of mesenteric hematomas, fat wall or mesenteric infiltration, bowel wall edema or thickening, or free peritoneal fluid. This poses a diagnostic pictures or signs given the potential for delayed bowel ischemia, hemorrhage or perforation and chemical peritonitis.

In our study, the decision for exploration and surgery on patients treated conservatively was based on repeated clinical, laboratory and radiologic examinations tests.

Because the bowel trauma may be occurred either combined or an isolated injury. Mental changes and consciousness and masked symptoms may decrease or inhibit the reliability of clinical physical examinations. Therefore, laboratory testing and CT scans must be done to make an accurate decision.

Repeat CT scans can provide good definite data in patients with suspected bowel injuries and resolved signs without surgery [13-14]. CT images were used in all patients that revealed positive signs in some cases with definitive radiologic evidence of bowel injury or perforation signs. The definite radiological pictures may be delayed until progression of bowel injury appeared. So, repeat CT scans are recommended with early suspected bowel injury after blunt abdominal trauma or multiple traumas with suspected abdominal injury.

Diagnostic laparoscopy is a rapid good and save treatment option in these patients [15, 16]. Except for general anesthesia that potentially aggravates the patient general condition, with the risk of unnecessary procedure.

Also the complication from laparoscopic procedures may interfere with the spontaneous healing and recover process that deteriorate bleeding focus from the pneumoperitoneum, or iatrogenic another injury for weak friable tissue.

So, the initial nonoperative approach for suspected bowel injury (that not proved) seems to increase the rate of delayed diagnosis and time factors to reduce morbidity or mortality. Long interval between presentation (definite injury) and surgery was found to be associated with many complications $[17,18]$. However, in this study, no any difference was found in postoperative complications between two operated groups (delayed or urgent surgery). The full data about the risk factors of delayed surgery is not fully evaluated due to relatively small number of patients. Among 44 patients with initial conservative therapy, 20 (45\%) underwent delayed surgery and all negative patients not need any procedure after exploration were 5 patients in group A and 15 patients of group B with total 20 patients 
of 81 blunt trauma patients(24.6\%). The proportion of patients with delayed surgery got increased as the radiological signs advanced (Table 4)

Table 4:-The relationship between the number of radiologic signs and delayed surgery

\begin{tabular}{|l|l|l|}
\hline signs number & Patients number & Surgery cases operated \\
\hline 1 & 10 & 3 \\
\hline 2 & 24 & 10 \\
\hline$>3$ & 10 & 8 \\
\hline Total & 44 & 20 \\
\hline
\end{tabular}

Additionally, patients with delayed surgery was younger age (37 years vs. 49 years) and higher WBC at admission (13.1 vs. 9.8 103/L) than patients without surgery, but without statistically significant.

Inevitable the missing rate as accurate diagnosis of bowel injury is challenging. So, many patients may undergo the risk of unnecessary surgery or invasive procedures. This can be significant for patient management conservative without progressive signs of radiology or laboratory or positive signs of physical abdominal examination, we suggest that bowel trauma may resolve spontaneously but if the clinical, radiological and laboratory signs compatible with mild non progressive injury. The conservative treatment based on the missed injuries is gradually advanced and gives rapid positive data in progression [19, 20]

Moreover, the outcome of delayed diagnosis and surgery is not always very bad [21]. The rate of missed injuries after early and initial evaluation may be decreased by the use of advanced technology, and the risk of delayed diagnosis will reduced by improvements of intensive care unit [22, 23]

\section{Conclusion:-}

It is not be possible to eliminate negative surgical exploration, but you can minimize it by selective delayed surgical intervention.

Our retrospective review revealed that 20 patients (5 group A and 15 group B) $24.6 \%$ negative patients. Depending on clinical pictures the decision of conservative line done in the treatment of hemodynamically stable patients with suspected traumatic bowel injuries rests with surgeon without definite radiological signs of urgent exploration correlated with laboratory and repeated physical examination, so, initial conservative management with selective delayed surgery is a good treatment option to avoid unnecessary surgery and hazards of urgent surgery.

\section{References:-}

1. Pal JD, Victorino GP. Defining the role of computed tomography in blunt abdominal trauma: use in the hemodynamically stable patient with a depressed level of consciousness. Arch Surge 2002; 137:1029-1032.

2. Petrosoniak A, Engels PT, Hamilton P, Tien HC. Detection of significant bowel and mesenteric injuries in blunt abdominal trauma with 64-slice computed tomography. J Trauma Acute Care Surg 2013; 74:1081-1086.

3. Joseph DK, Kunac A, Kinler RL, Staff I, Butler KL. Diagnosing blunt hollow viscus injury: is computed tomography the answer? Am J Surg 2013; 205:414-418?

4. Brownstein MR, Bunting T, Meyer AA, Fakhry SM. Diagnosis and management of blunt small bowel injury: a survey of the membership of the American Association for the Surgery of Trauma. J Trauma 2000; 48:402-407.

5. Sherck J, Shatney C, Sensaki K, Selivanov V. The accuracy of computed tomography in the diagnosis of blunt small-bowel perforation. Am J Surge 1994; 168:670-675.

6. Ekeh AP, Saxe J, Walusimbi M, Tchorz KM, Woods RJ, and Anderson HL 3rd, et al. Diagnosis of blunt intestinal and mesenteric injury in the era of multidetector CT technology: are results better? J Trauma 2008; 65:354-359.

7. Bhagvan S, Turai M, Holden A, Ng A, Civil I. Predicting hollow viscus injury in blunt abdominal trauma with computed tomography. World J Surg 2013; 37:123-126.

8. Mahmoud I, Tewfik Z, Abdelrahman Y, Siddiuqqi T, Abdelrahman H, El-Menyar A, et al. Significance of computed tomography finding of intra-abdominal free fluid without solid organ injury after blunt abdominal trauma: time for laparotomy on demand. World J Surg 2014; 38:1411-1415.

9. Fischer RP, Miller-Crotchett P, Reed RL 2nd. Gastrointestinal disruption: the hazard of nonoperative management in adults with blunt abdominal injury. J Trauma 1988; 28:1445-1449. 
10. Fakhry SM, Brownstein M, Watts DD, Baker CC, Oller D. Relatively short diagnostic delays (<8 hours) produce morbidity and mortality in blunt small bowel injury: an analysis of time to operative intervention in 198 patients from a multicenter experience. J Trauma 2000; 48:408-414.

11. Malinoski DJ, Patel MS, Yakar DO, Green D, Qureshi F, Inaba K, et al. A diagnostic delay of 5 hours increases the risk of death after blunt hollow viscus injury. J Trauma 2010; 69:84-87.

12. Ozturk H, Dokucu AI, Onen A, Otcu S, Gedik S, Azal OF. Non-operative management of isolated solid organ injuries due to blunt abdominal trauma in children: a fifteen-year experience. Eur J PediatrSurg 2004; 14:29-34.

13. Sim J, Lee J, Lee JC, Heo Y, Wang H, Jung K. Risk factors for mortality of severe trauma based on 3 years' data at a single Korean institution. Ann Surg Treat Res 2015; 89:215-219.

14. Walker ML, Akpele I, Spence SD, Henderson V. The role of repeat computed tomography scan in the evaluation of blunt bowel injury. Am Surg 2012; 78:979-985.

15. Kaban GK, Novitsky YW, Perugini RA, Haveran L, Czerniach D, Kelly JJ, et al. Use of laparoscopy in evaluation and treatment of penetrating and blunt abdominal injuries. SurgInnov 2008; 15:26-31.

16. Johnson JJ, Garwe T, Raines AR, Thurman JB, Carter S, Bender JS, et al. The use of laparoscopy in the diagnosis and treatment of blunt and penetrating abdominal injuries: 10-year experience at a level 1 trauma center. Am J Surg 2013; 205:317-320.

17. Faria GR, Almeida AB, Moreira H, Barbosa E, Correia-da-Silva P, Costa-Maia J. Prognostic factors for traumatic bowel injuries: killing time. World J Surg 2012; 36:807-812.

18. Matsushima K, Mangel PS, Schaefer EW, Frankel HL. Blunt hollow viscus and mesenteric injury: still under recognized. World J Surg 2013; 37:759-765.

19. Subramanian V, Raju RS, Vyas FL, Joseph P, Sitaram V. Delayed jejunal perforation following blunt abdominal trauma. Ann R CollSurgEngl 2010; 92:W23-W24.

20. Ertugrul G, Coskun M, Sevinc M, Ertugrul F, Toydemir T. Delayed presentation of a sigmoid colon injury following blunt abdominal trauma: a case report. J Med Case Rep 2012; 6:247.

21. Letton RW Jr, Worrell V, Tuggle DW. American Pediatric Surgical Association Committee on Trauma Blunt Intestinal Injury Study Group. Delay in diagnosis and treatment of blunt intestinal perforation does not adversely affect prognosis in the pediatric trauma patient. J Trauma 2010; 68:790-795.

22. Al-Hassani A, Tuma M, Mahmood I, Afifi I, Almadani A, El-Menyar A, et al. Dilemma of blunt bowel injury: what are the factors affecting early diagnosis and outcomes. Am Surg 2013; 79:922-927.

23. ChichomMefire A, Weledji PE, Verla VS, Lidwine NM. Diagnostic and therapeutic challenges of isolated small bowel perforations after blunt abdominal injury in low income settings: analysis of twenty three new cases. Injury 2014; 45:141-145. 